\title{
NANISMO - A MODA ALIADA A ERGONOMIA COMO FATOR DE INCLUSÃO
}

\author{
Dwarfism - the fashion allied with ergonomics as a factor of inclusion
}

\author{
BALLEN, Clarissa Francener; Graduanda; Univille \\ clarissafrancenerballen@gmail.com \\ GONÇALVES, Gabriella Oliveira; Graduanda; Univille \\ gabriellaog1@gmail.com \\ POFFO, Caroline; Graduanda; Univille \\ caroline.poffo.1@gmail.com \\ RIBEIRO, Mariê Souza; Mestra; Univille \\ marie.ribeiro91@gmail.com \\ DICKIE, Isadora Burmeister, Doutora, Univille \\ isadora.dickie@gmail.com
}

\section{Resumo}

Este artigo apresenta o desenvolvimento de uma calça para mulheres com nanismo, visto que é um público pouco atendido. O objetivo da pesquisa foi estudar e entender o nanismo, suas características e particularidades para que, aliado ao conhecimento de moda e de ergonomia, pudesse gerar uma solução de vestuário. Desse modo, foram empregados métodos de revisão bibliográfica, análise de similares, além de entrevista e questionário junto ao público-alvo. Em suma, foram levados em consideração os fatores ergonômicos, psicológicos, mercadológicos e sociais, resultando na confecção de uma calça com as principais tendências do verão 2018.

Palavras Chave: nanismo, moda inclusiva, ergonomia.

\section{Abstract}

This article presents the development of a pant for women with dwarfism, since it is an underserved public. The objective of the research was to study and understand dwarfism, its characteristics and particularities, so that, allied with the knowledge of fashion and ergonomics, could generate a garment solution. Methods of bibliographic review were used, similar analysis besides interviews and questionnaires along with our target public. Ergonomic, psychological, market and social factors were taken into consideration, resulting in the designing of a pant with the main fashion tendencies in summer 2018.

Keywords: dwarfism, inclusive fashion, ergonomics. 


\section{Introdução}

Os vestuários atualmente não servem apenas para proteção, eles têm papel fundamental nas interações sociais. Além do mais, as roupas são instrumentos para que se possa fazer a análise da personalidade de determinado indivíduo. Porém, no ambiente fashion, nem todos conseguem se vestir como gostariam e, geralmente, se vestem com as roupas que servem (comumente peças de roupas e/ou sapatos infantilizados) e outras vezes precisam passar por uma costureira para fazer alguns ajustes, na intenção de que a peça sirva perfeitamente. Porém, nem sempre são ajustes satisfatórios, uma vez que, ao fazê-los, pode-se mexer no caimento da peça, o que poderá deixá-la desconfortável ou não tão agradável esteticamente.

No Brasil, há aproximadamente 125.323 pessoas com nanismo. Muitas dessas relatam algum tipo de dificuldade em encontrar uma peça de roupa ou um sapato que não seja do departamento infantil, principalmente no caso do sapato. Considera-se que, além de sofrer com algum distúrbio psicológico, estas pessoas possam vir a se sentir mais afetadas ou diminuídas por não haver uma moda mais inclusiva que permita a elas que se vistam conforme as tendências, ou que possam escolher de forma mais livre as roupas que irão usar.

Existem poucos estudos na área da moda, por exemplo, o estudo de Camargo e Valente (2011) e Körbes, Laschuk e Costa (2015), que são mais abrangentes. E se faz necessário estudar mais sobre essa parte da população, que também trabalha e consome artigos de vestuário. A expectativa de vida de pessoas com nanismo é a mesma que a expectativa de vida de uma pessoa com estatura normal. Isso torna estas pessoas possíveis consumidores fiéis de uma marca, e assim, justifica as lojas possuírem uma parte dos departamentos voltada para este público.

Além de contribuir com o meio acadêmico e mercadológico, este trabalho objetiva também abranger a parte social, à qual a moda se liga intimamente. $O$ discurso de representatividade se aplica à moda, independente se pensarmos em pessoas com nanismo, pessoas com dificuldades motoras ou pessoas com sobrepeso, por exemplo. A moda tem um papel fundamental na sociedade, como dito anteriormente, pois colabora de maneira significativa nas interações sociais. Além disso, pretende-se fazer um estudo ergonômico, de informações que já existem e verificar sua conformidade com a realidade por meio de comparações, e aplicar esses estudos à produção de algumas peças (bem como a sua modelagem) de acordo com as principais tendências de moda (neste estudo, para o verão 2018).

\section{Pesquisa bibliográfica}

\subsection{Conhecimentos sobre a doença de modo geral e específico dentro do campo da moda}

Nanismo está relacionado à baixa estatura das pessoas. A forma mais comum é causada por hereditariedade, mas pode ser causada também por mutações genéticas ou por disfunções do hormônio do crescimento (Varella, 2017). Pessoas com nanismo têm, em média, $1,20 \mathrm{~cm}$ de altura. Segundo Varella (2017), existe cerca de 200 tipos de doenças que acometem o crescimento, sendo que o mais comum é o nanismo, e derivando do mesmo, existe a acondroplasia, que faz parte do nanismo desproporcional. Segundo o estudo da Dra. Betty M. Adelson (2005), em média, a cada 1657 nascimentos, um é portador da deficiência. Levando em conta este estudo, o Brasil soma, em média, cerca de 125 mil pessoas com nanismo. 
Essas pessoas são chamadas informalmente por anões, palavra que os mesmos rejeitam, pois é usada, geralmente, de maneira pejorativa. As piadas de mau gosto e o preconceito gerado em torno da aparência afetam e levam a complexos de inferioridade e baixa autoestima, tornando-os, por vezes, antissociais. Sendo o nanismo causado por um distúrbio autossômico (Varella, 2017), ele não vem acompanhado por distúrbios psicológicos de forma orgânica, porém, devido às privações sociais e a construção histórica dos indivíduos portadores, geralmente acabam por desenvolvê-los.

Tendo conhecimento desses dados, percebeu-se a necessidade de pesquisar sobre o público em questão dentro do campo da moda. Fez-se uma busca rápida por desfiles ou peças de vestuário pensadas para atender somente ao público com nanismo, não se encontraram mais do que quatro desfiles. Um promovido por alunas de um curso de Moda no estado de Minas Gerais (imagem 01) em 2010 (Lagôa, 2010). Outro que ocorreu em diversas cidades (imagem 02), nomeado "Dwarf Fashion Show" com modelos criados pela agência nova-iorquina Creative Business House, fundada por Myriam Chalek, em 2015, no qual contava com um casting de 10 modelos com nanismo, não profissionais e de diversas regiões do mundo. $O$ intuito era, além de debater sobre a moda inclusiva, fomentar nestas mulheres a confiança e discutir sobre a igualdade na moda $(\mathrm{G} 1,2015)$.

Imagem 01 - Modelo desfila em universidade.

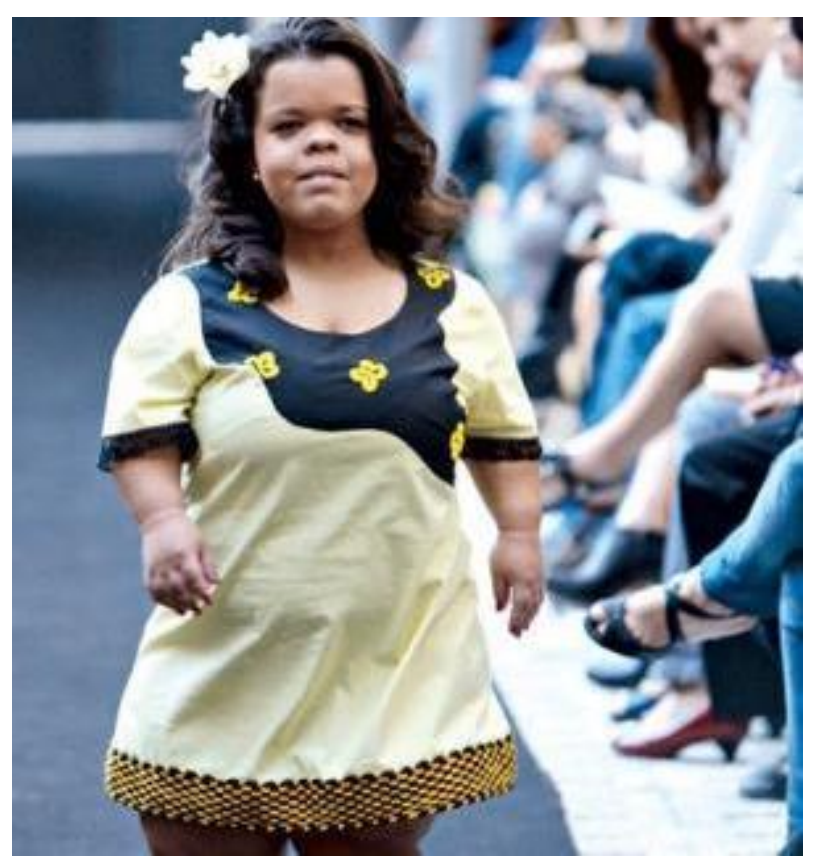

Fonte: O Tempo (2010). 


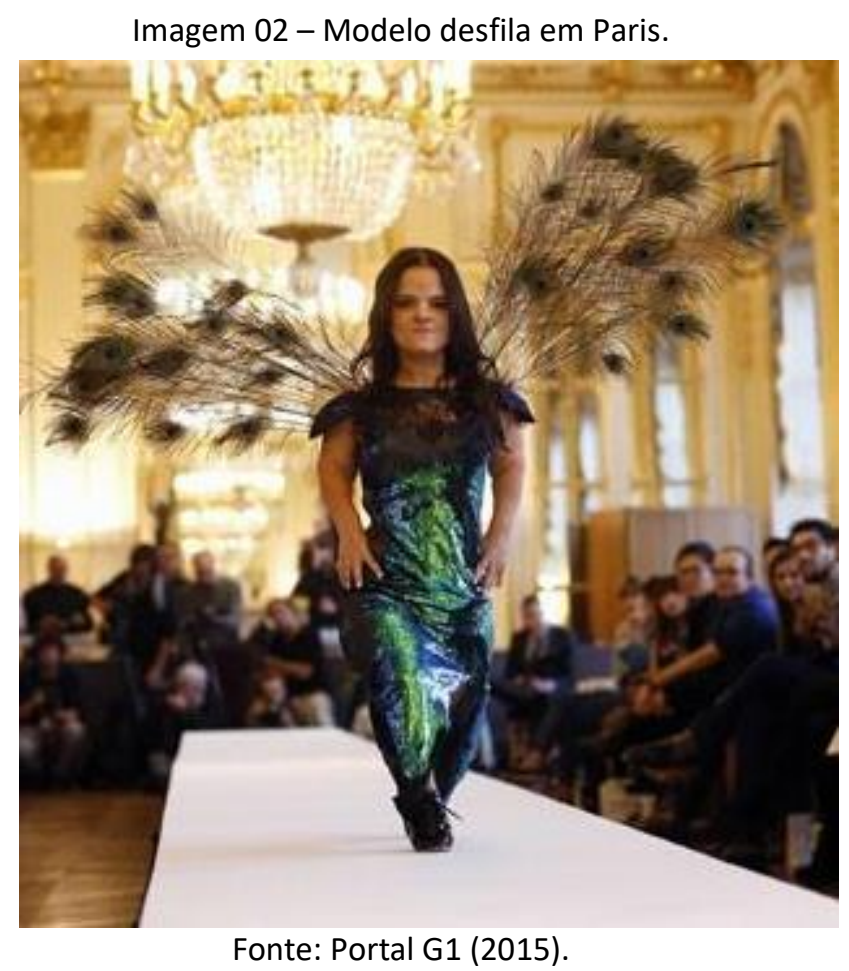

Por fim, um desfile que ocorreu tanto em São Paulo, como no Rio de Janeiro (imagens 03 e 04), em 2010 e 2016 respectivamente, com roupas criadas pelas mãos da estilista paulista Carina Casuscelli com a coleção "A Moda Está em Baixa" (Portal G1). Entende-se que existe uma necessidade de olhar e evidenciar cada vez mais esse público, que não está à margem da sociedade, mas está à margem da moda como um todo. Na imagem 03, Casuscelli posa ao lado de uma das suas modelos, e na imagem 04 a modelo com nanismo posa durante desfile.

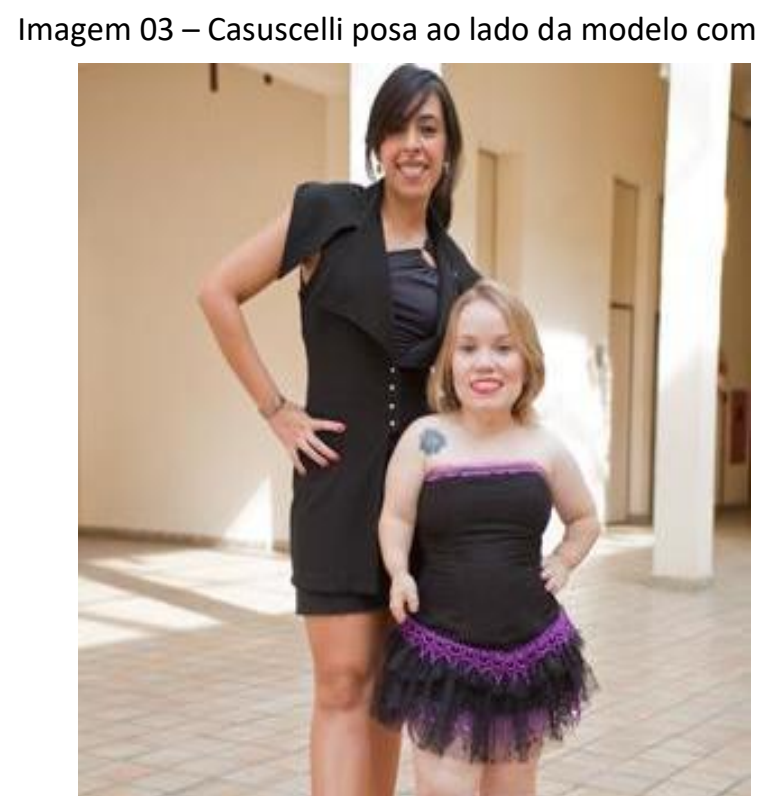

Fonte: Portal G1 (2011). 


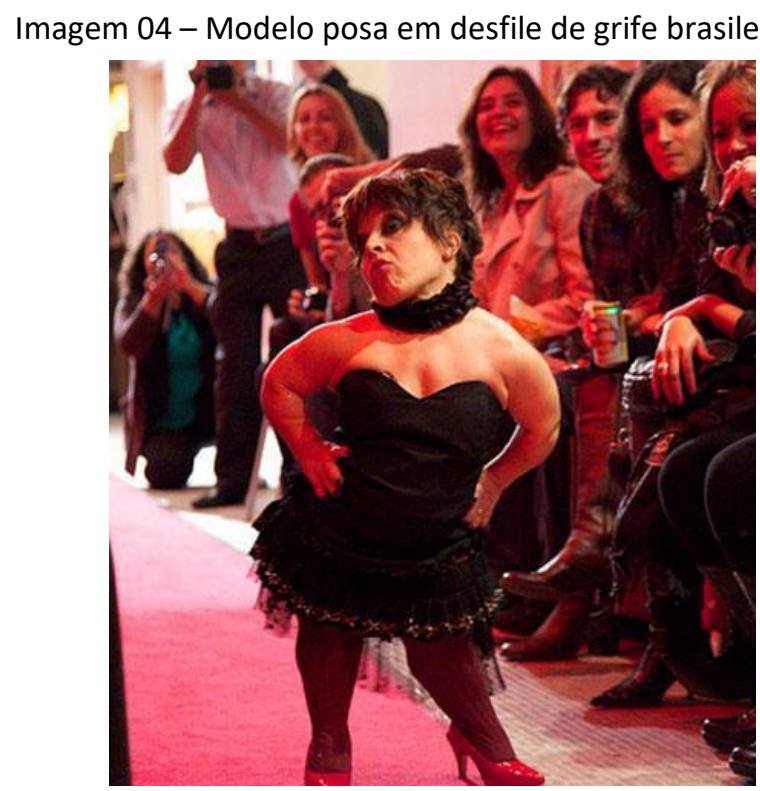

Fonte: Portal G1 (2011).

Carina Casuscelli é uma das poucas designers que conseguiu entender as dificuldades das mulheres com a deficiência, investindo para produzir uma grife que gere lucro e que incentive uma luta pela democratização da moda (Gasparin, 2011). A estilista garante que pretende investir ainda mais na marca "A moda está em Baixa" (Büll, 2018).

Todas as reportagens encontradas sobre o assunto, que possuíam entrevistas com criadores, participantes ou com o público, abordam sempre os mesmos problemas: a dificuldade em encontrar vestuário específico para esse público e como é difícil se sentir parte do todo quando não existem modelagens que são pensadas para as mulheres com nanismo.

Assim, partiu-se para a segunda etapa da pesquisa bibliográfica, a fim de identificar os principais requisitos que devem ser considerados na criação de vestuário para pessoas com nanismo.

\subsection{Requisitos ergonômicos na criação de vestuário para pessoas com nanismo}

De acordo com a Revista da Associação Brasileira de Ergonomia:

Ergonomia (ou fatores humanos) é a disciplina científica que trata da compreensão das interações entre os seres humanos e outros elementos de um sistema, e a profissão que aplica teorias, princípios, dados e métodos, a projetos que visam otimizar o bem estar humano e a performance global dos sistemas. (ABERGO, 2008)

Então a ergonomia, segundo a $A B E R G O$, é o estudo da interação do homem com o produto. $E$ para o produto, neste caso um artigo de moda, alguns dos requisitos ergonômicos a serem considerados no projeto são os requisitos físicos. Segundo Sabrá (2009), os fatores físicos ocupamse das características da anatomia humana, antropometria e biomecânica relacionadas com a atividade física. Já os fatores mentais, Sabrá (2009) explica que "corresponde aos aspectos mentais, como a percepção, memória, raciocínio e resposta motora, relacionados às pessoas e a outros elementos de um sistema". Na produção das peças foram considerados quatro requisitos: antropometria, biomecânica, fisiologia, e conforto físico e mental. 
Desta forma, a partir dos requisitos citados acima, foi possível desenvolver peças para o público-alvo, respeitando seus desejos, limitações e necessidades. Isso inclui a elevação da autoestima e da autoconfiança, atreladas ao ato de vestir-se com artigos personalizados e destinados ao seu nicho de pertencimento.

Para compreender melhor esses desejos, limitações e necessidades, realizou-se uma coleta de dados com o público, por meio de entrevistas e questionários.

\section{Pesquisa de campo}

\subsection{Questionário}

Para obter mais informações sobre o público alvo, além das pesquisas bibliográficas, realizouse um questionário e uma entrevista. O questionário foi aplicado a partir do Google Formulários e contou com dez respostas. $\mathrm{O}$ objetivo era esclarecer dúvidas quanto às dificuldades encontradas pelo público.

Entre as dez pessoas respondentes, sete estavam entre 17 e 35 anos; a altura média entre as mulheres respondentes foi $1,20 \mathrm{~m}$. Quando perguntadas sobre dificuldades em encontrar roupas e estilos disponíveis para o seu tamanho, nove pessoas disseram que a calça era a maior dificuldade, e cinco delas responderam que seu estilo era casual, mas que também preferiam tecidos leves e mais confortáveis. Oito delas também responderam que ao ter que realizar ajustes nas peças, elas perdiam o caimento original e parte da modelagem. Descobriu-se também que cinco destas mulheres preferem comprar roupas em lojas localizadas no centro da cidade, sendo que a minoria optou entre lojas de departamento e lojas de bairro. E por fim, três mulheres relataram que já compraram roupas que não precisaram ser ajustadas.

De posse dessas respostas, optou-se pela realização de uma calça, que estivesse de acordo com as tendências verão 2018, e que possuísse como características a casualidade e o conforto.

\subsection{Entrevista}

A representante do público alvo entrevistada é uma mulher de 21 anos, estudante do último ano de Administração e empregada de uma grande empresa. Ela trabalha em tempo integral e estuda à noite. No primeiro encontro, a entrevistada relatou que calças realmente era sua principal dificuldade, mas revelou que casacos e jaquetas também precisam ser levados para as costureiras adaptarem, devido ao tamanho dos membros superiores também serem menores em relação aos não-acondroplásicos. O manequim da entrevistada costuma ser entre o tamanho $36 \mathrm{e}$ 38 no seu tronco.

Falou de forma espontânea que sua mãe também tem nanismo e relatou que está fazendo reeducação alimentar, por isso está diminuindo o tamanho do seu manequim. Além disso, informou que camisetas e blusas não costumam precisar de ajustes. Segunda a mesma, ela tem um estilo básico. Possui amplitude de movimentos regular, e não relatou nenhuma dificuldade em relação à ação de vestir a calça, que é normal como qualquer outra pessoa. Brincou com o fato de apenas não conseguir alcançar objetos altos. Durante os encontros com a entrevistada, observouse atentamente as dificuldades de locomoção e possíveis dificuldades motoras não relatadas.

Referente a entrevista, perguntou-se à entrevistada qual a preferência dela por modelagens e 
tecidos. Ela disse que preferia calça jeans skinny. Perguntou-se se ela tinha preferência por algum tipo específico de aviamento, e ela respondeu botão, relatando que é o mais fácil de manusear. Também se questionou se ela usava shorts, ela disse que sim, preferencialmente com o comprimento abaixo do joelho. E ainda no quesito calça, ela mencionou que gosta de calças que possuem bolsos. Foi necessário mais de um encontro para complementar as informações obtidas, já que foi preciso também tirar as medidas dela e validar soluções encontradas.

\subsection{Análise Antropométrica}

Além da aplicação de questionários e realização da entrevista, percebeu-se a necessidade de coletar informações referentes às medidas da representante do público, a fim de desenvolver a peça com as medidas e caimento corretos, e compreender melhor a estrutura física de pessoas com nanismo. Para isso, coletaram-se as medidas (imagem 05) da mesma mulher escolhida para a realização da entrevista. A partir dessas medidas, fez-se a comparação com as medidas obtidas no estudo de Camargo e Valente (2014) (imagem 06). As medidas foram feitas apenas na parte inferior, e com base nas tabelas, foi concluído que a entrevistada correspondia ao tamanho M. Além disso, foi considerado também o fato que nem todas as mulheres com nanismo possuem a mesma amplitude de movimentos que pessoas sem nanismo. O que pode ser causado por uma doença adversa ou pelo fato dos braços serem pequenos e desproporcionais.

Imagem 05 - obtida a partir das medidas da entrevistada.

\begin{tabular}{|c|c|}
\hline $\begin{array}{c}\text { TABELA DE MEDIDAS DA EN TREVISTADA } \\
\text { PARTE INFERIOR DO CORPO }\end{array}$ & $\mathbf{C M}$ \\
\hline QUADRIL & 107 \\
\hline COMP. CALÇA & 60 \\
\hline CIRC. COXA & 60 \\
\hline COMP. GANCHO & 49 \\
\hline COMP. CINTURA AO JOELHO & 42 \\
\hline
\end{tabular}

Fonte: autoras (2017).

Imagem 06 - Medidas obtidas na pesquisa de Camargo e Valente.

\begin{tabular}{|c|c|c|c|}
\hline \multicolumn{4}{|c|}{$\begin{array}{c}\text { TABELA DE MEDIDAS ESPECIFICA PARA } \\
\text { PORTADORAS DE ACONDROPLASIA } \\
\text { Valores em cm }\end{array}$} \\
\hline \multicolumn{3}{|c|}{ MEDIDAS DA PARTE INFERIOR DO CORPO } \\
\hline & P & M & G \\
\hline QUADRIL & 82 & 100 & 122 \\
\hline COMP. PERNAS & 47 & 54 & 64 \\
\hline CIRC. COXA & 49 & 56 & 63 \\
\hline $\begin{array}{c}\text { COMP. GANCHO } \\
\text { TOTAL }\end{array}$ & 40 & 47 & 55 \\
\hline $\begin{array}{c}\text { COMP. CINTURA AO } \\
\text { JOELHO }\end{array}$ & 25 & 28 & 34 \\
\hline
\end{tabular}

Fonte: Camargo e Valente (2011). 
Todas essas informações coletadas, juntamente com o questionário e a entrevista foram utilizadas para a definição da persona.

\subsection{Definição da persona}

Utilizando as informações obtidas no questionário e durante a entrevista, definiu-se uma persona para a criação da peça. Na imagem 07, encontra-se o painel da persona. A seguir, apresenta-se a persona:

Lara tem 21 anos, é solteira, trabalha e estuda. Ela tem um dia longo, acorda cedo e dorme tarde. Gosta de passear com a família nos fins de semana e de sair à noite com seus amigos. Lara também se preocupa com a saúde e com a sua imagem pessoal. Possui um estilo casual e básico, e gosta de roupas que sejam confortáveis. Prefere comprar roupas em lojas do seu bairro ou em lojas de departamentos. Como precisa enviar as peças que compra para a costureira fazer as adaptações, ela não costuma gastar muito dinheiro com as suas peças, optando por valores mais acessíveis.

Imagem 07 - Painel de persona.

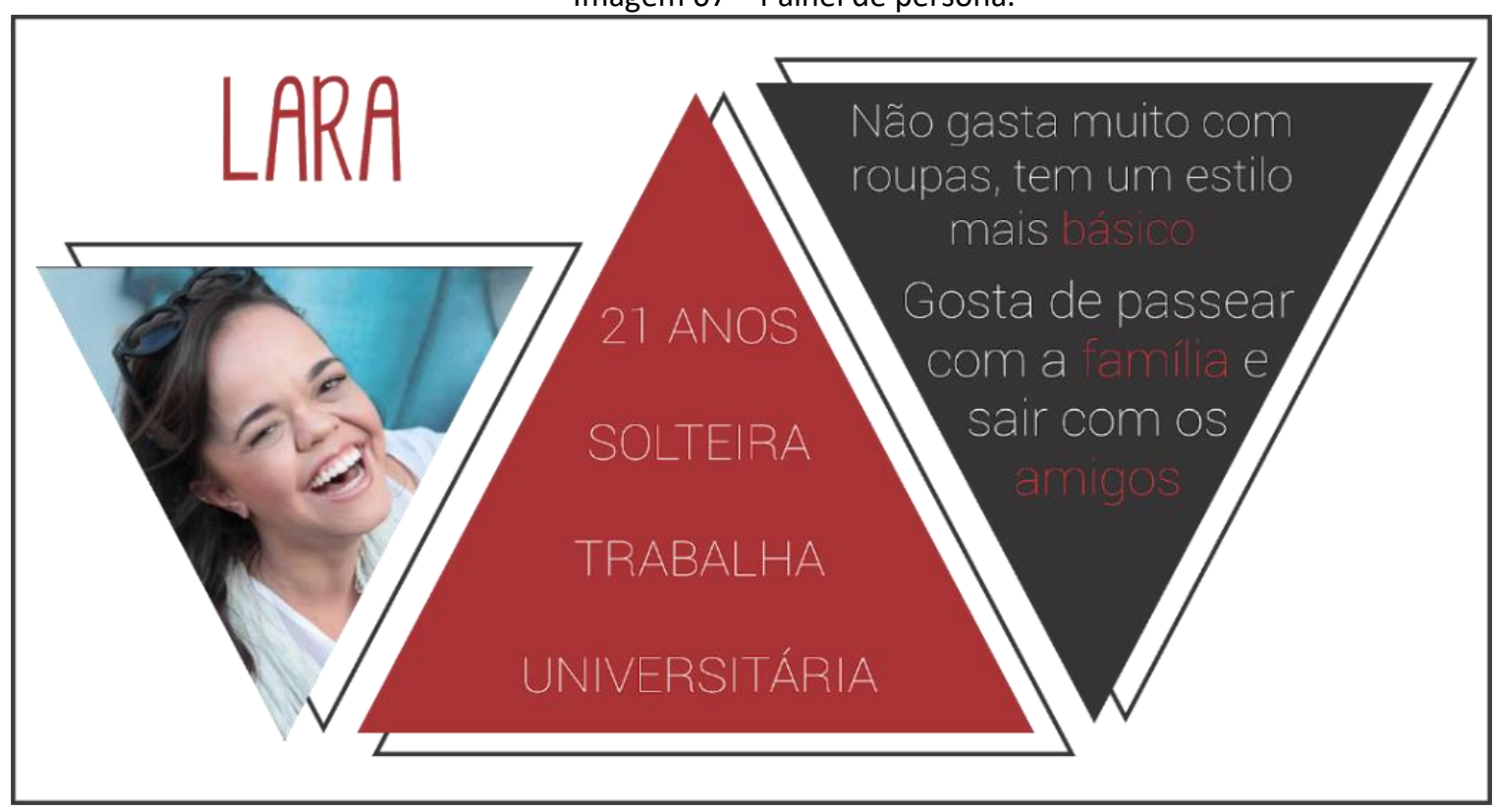

Fonte: autoras (2017).

\subsection{Pesquisa de tendências}

Para a presente pesquisa, buscaram-se informações sobre as tendências de moda para o verão 2018/2019. Essa estação traz blocos contrastantes com cores vibrantes, que são inseridas em combinações monocromáticas e minimalistas, dando um ar de sustentabilidade no reaproveitamento de retalhos que se encaixam, criando novos desenhos geométricos. Na modelagem tem a assimetria, tanto na região dos decotes, quanto nos comprimentos e barras das peças. Outra forma de se trabalhar com a assimetria é por meio dos recortes. Além disso, os aviamentos também seguem um visual mais discreto, como zíperes com fechos diferenciados, fazendo com que eles transitem do escritório ao happy hour. As cores mencionadas são: verde, rosa, amarelo, cinza, vermelho e preto (Portal Use Fashion, 2017). Abaixo, na imagem 08, o painel 
de tendência ilustra das principais referências visuais encontradas.

Imagem 08 - Pesquisa de tendências.

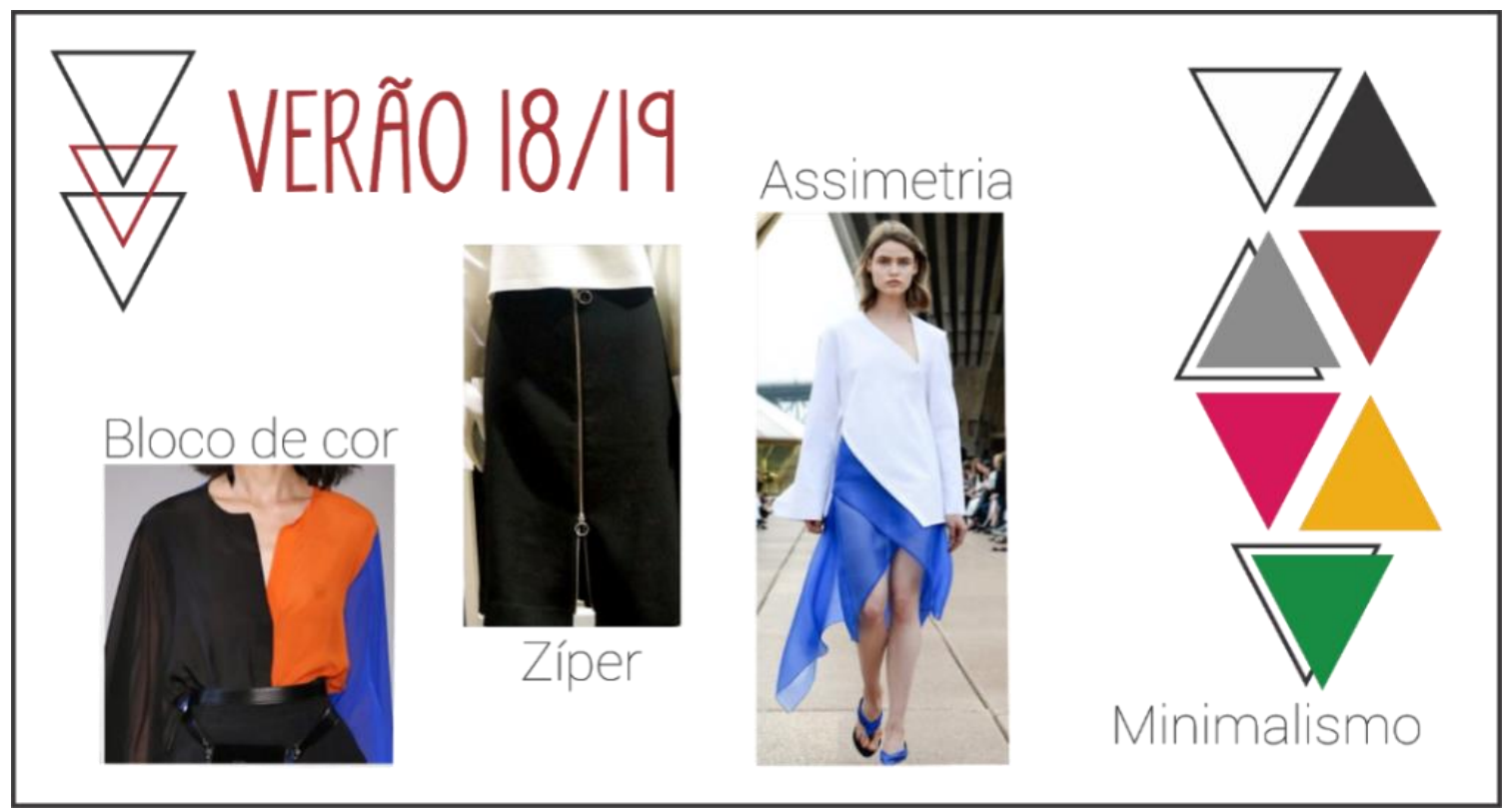

Fonte: autoras (2017).

\section{Desenvolvimento da Coleção}

\subsection{Conceito e tema}

Para desenvolver a peça, primeiro definiram-se os conceitos e tema da peça de vestuário. Entende-se que a Moda não é só para as mulheres altas das passarelas, pois todos gostam de ser atendidos pela indústria da moda. Essa peça de vestuário tenta trazer a mulher com nanismo para o meio fashion e intenciona dizer que a moda, além de ser para todos, é, também, um meio de aumentar a autoestima das mulheres que estão fora dos padrões.

Para isso, tem-se como referência a série Girlboss, que mostra uma mulher forte e independente. Mostra que o estilo próprio traz não só informação de moda, mas de vivência e dia-a-dia também. A inspiração vem da jovialidade que transmite essa mulher que independente das dificuldades, escolheu viver. E levou-se em consideração essa leveza da vida para fazer um look casual, mais básico para essas mulheres. Versatilidade é a palavra desse look. Na imagem 09, o painel do tema. 


\section{Imagem 09 - Painel de tema.}

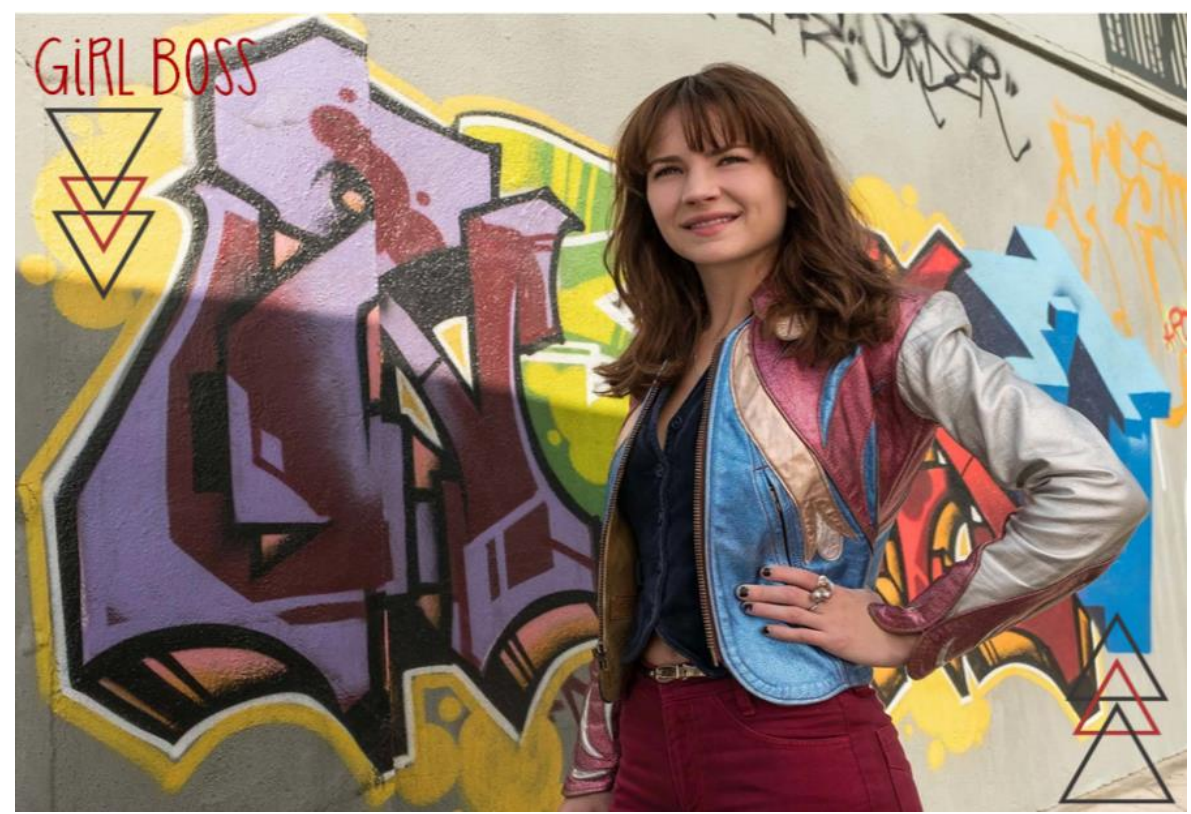

Fonte: autoras (2017).

\subsection{Cartela de cores e materiais}

Com base na pesquisa de tendências, no conceito e tema de coleção e nas respostas do público-alvo, definiram-se as cores e materiais da peça, priorizando o conforto físico e visual. As cores selecionadas foram o cinza, vermelho e preto. Optou-se pelos tecidos Sarja e Viscolycra, devido à elasticidade de forma que gerasse conforto, mesmo que usado ao longo do dia, e devido a sua versatilidade para ocasiões diversas. Para os aviamentos, botões e zíperes. Na imagem 10, a cartela de cores e materiais.

Imagem 10 - Cartela de cores e materiais.

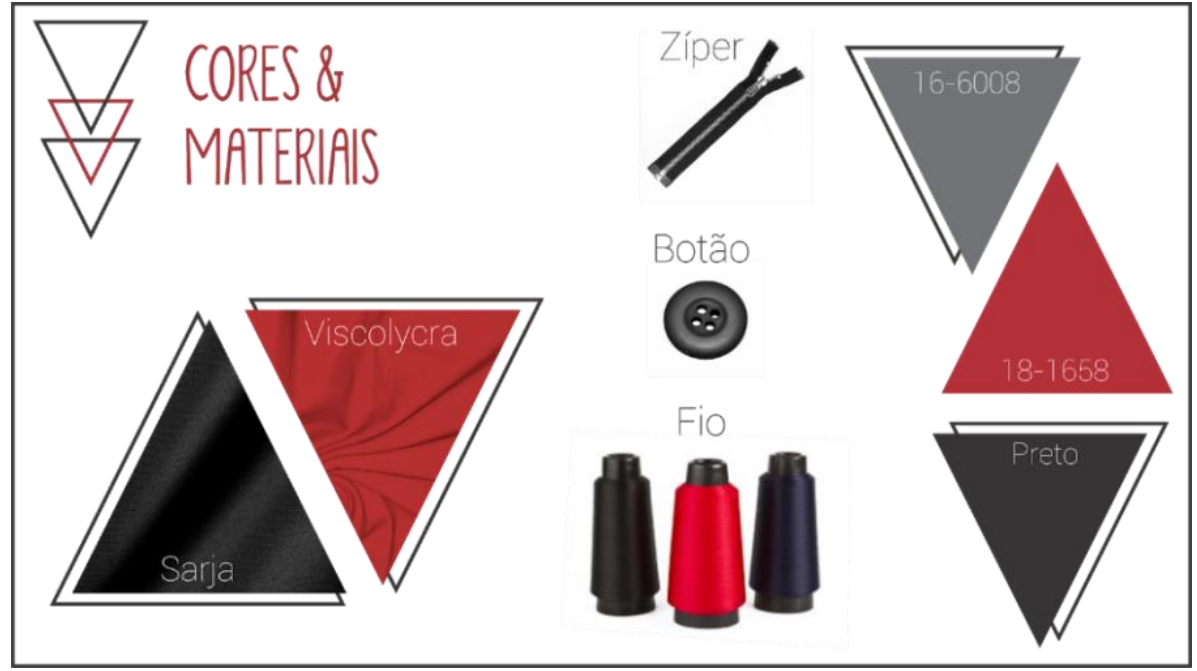

Fonte: autoras (2017). 


\section{Artigo Completo}

\subsection{Geração de alternativas}

Com base no questionário e na entrevista, definiram-se algumas prioridades que deveriam ser atendidas. A modelagem deveria ser adequada ao tamanho da pessoa com nanismo, visando sempre o conforto estético e físico. E além de pensar em modelagens exclusivas, adicionar à peça informações de tendências do verão 2018. Cada peça foi desenhada pensando nesses requisitos, que foram usados também para fazer a exclusão ou a aceitação da peça final, bem como modelagens que fossem mais fáceis de manusear devido às mãos pequenas e uma possível falta de amplitude nos movimentos superiores e inferiores. A geração de alternativas apresenta-se nas imagens $11,12,13$ e 14.

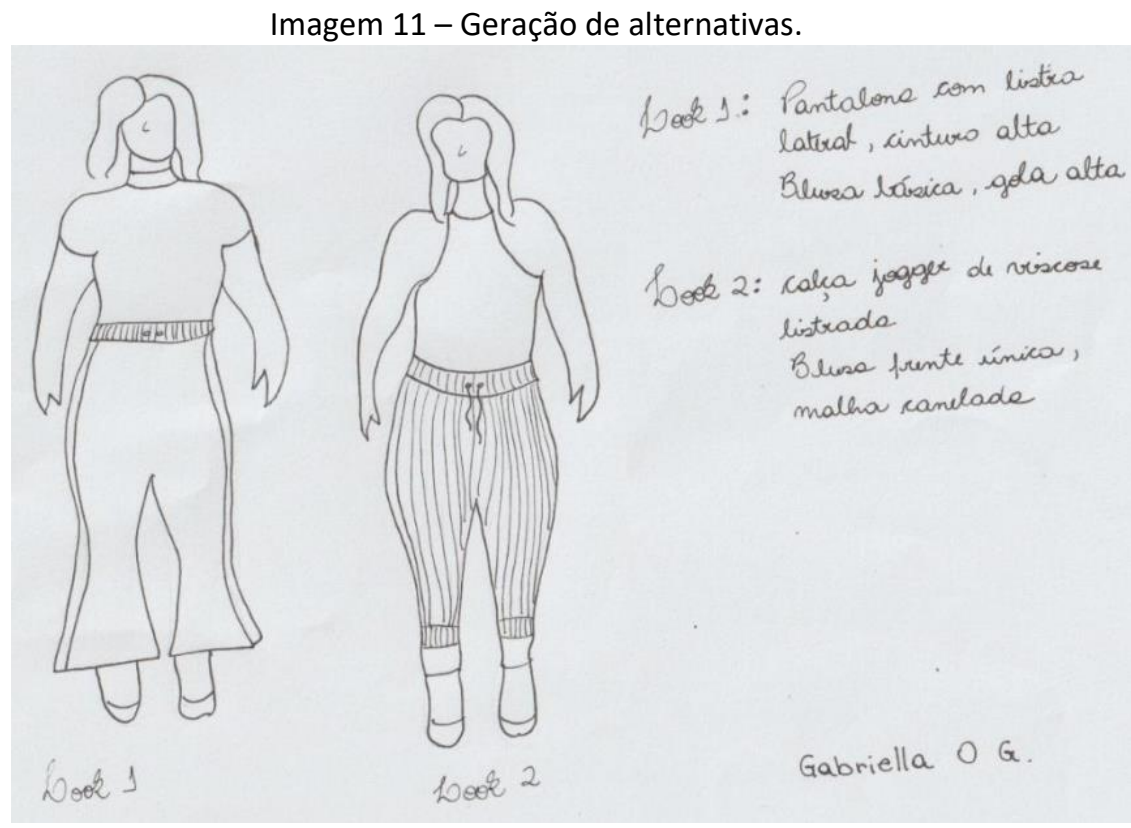

Fonte: autoras (2017).

Imagem 12 - Geração de alternativas.
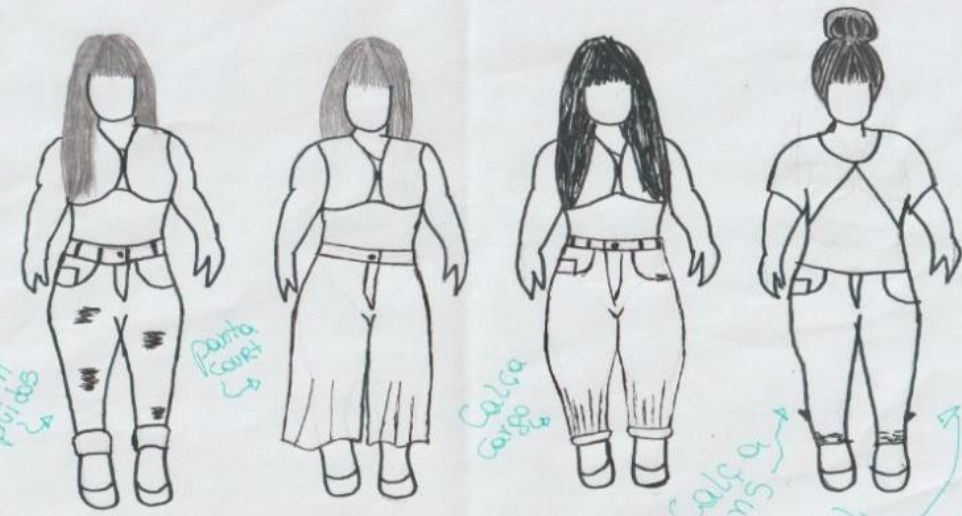

Fonte: autoras (2017). 


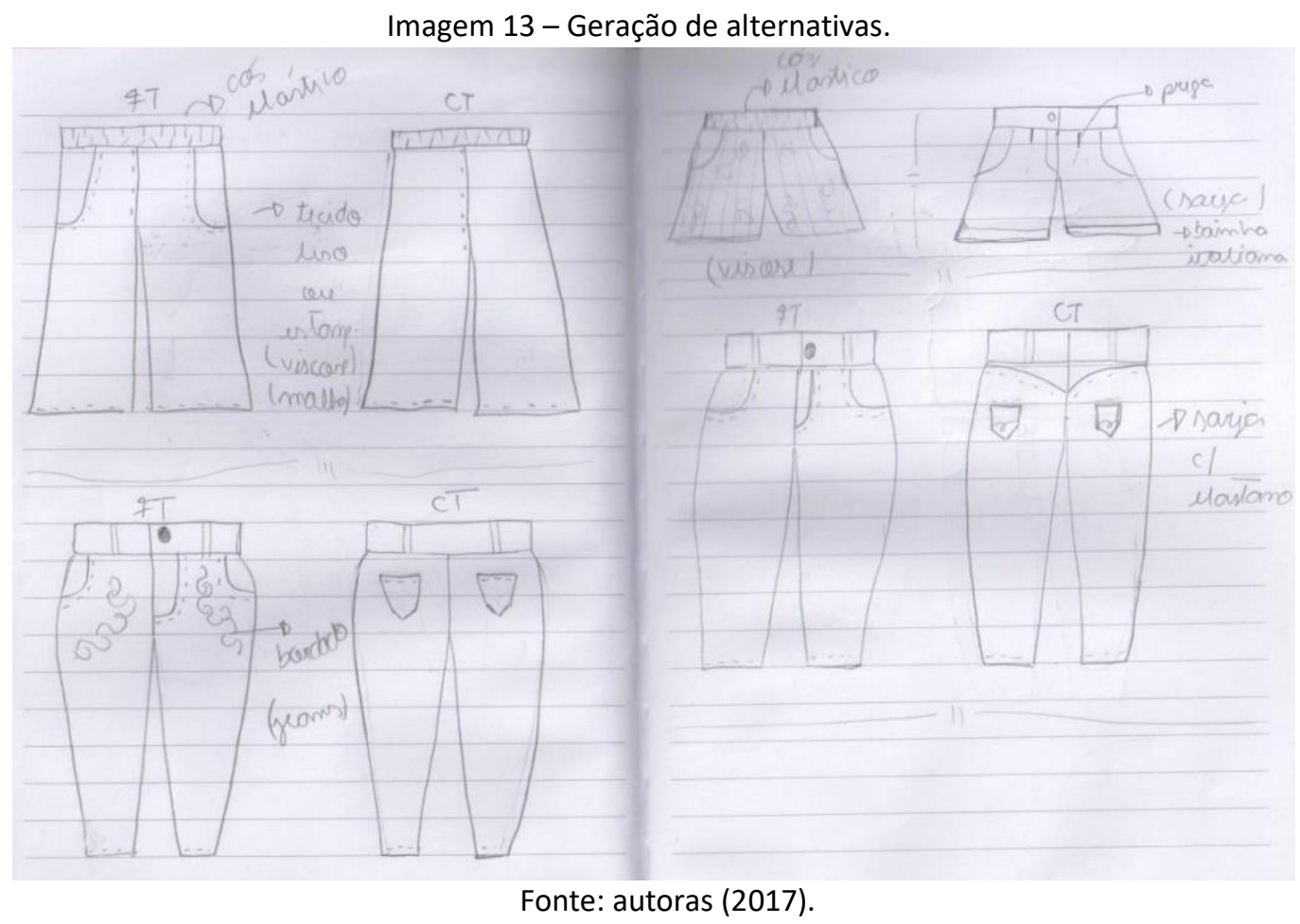

Imagem 14 - Geração de alternativas.

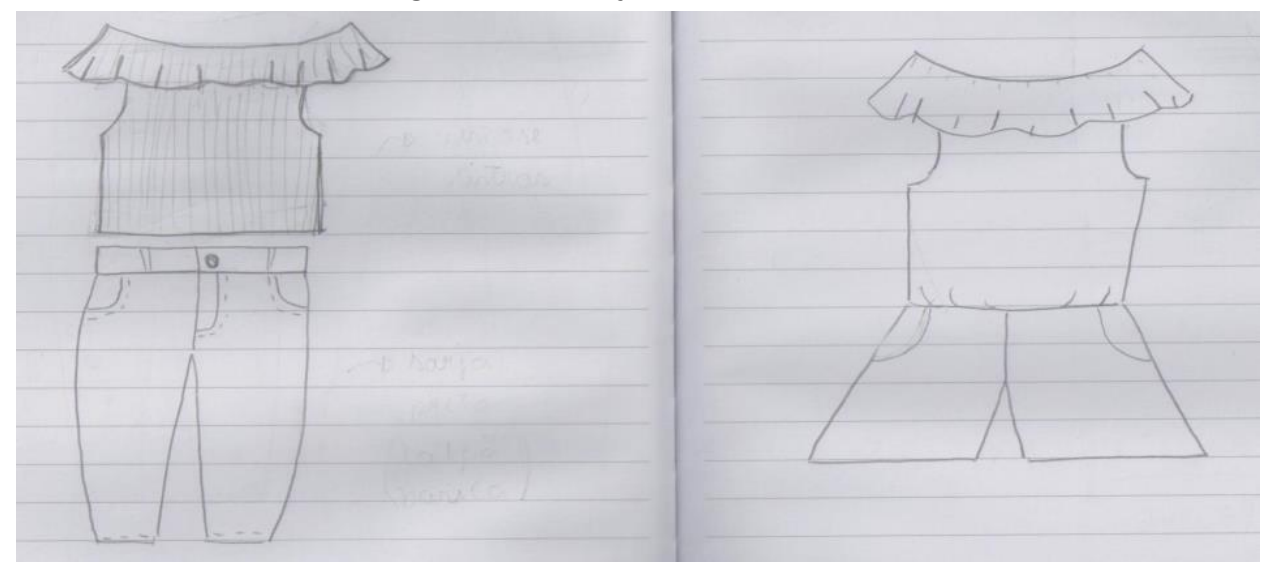

Fonte: autoras (2017).

A geração resultou em dez alternativas de calças/shorts e seis opções de blusas, contando com modelos variantes de calça pantalona, jogger, skinny, pantacourt, cargo, com diferentes materiais. E blusas de gola alta, cavada, formando blocos geométricos com o tecido e ciganinha.

\subsection{Look ou peça escolhida}

Para a escolha da peça, consideraram-se aspectos ergonômicos e visuais, como o público se sente mais confortável e quais as peças ficam melhores visualmente nos seus corpos. A atenção principal transcorreu para a calça, mas decidiu-se, também, confeccionar uma blusa que complementasse o look, para a produção das fotos.

$\mathrm{Na}$ calça (imagem 15) as informações de tendências foram adicionadas de forma sutil, de modo a manter a neutralidade da peça, podendo se adequar a mais de uma situação. $O$ tecido 
utilizado foi a sarja com elastano, visto que foi o substituto mais adequado que encontrou-se para o jeans, porquanto ele traria maior conforto à peça. Conforme a pesquisa, pessoas com nanismo podem apresentar dificuldades no que diz respeito à amplitude de movimentos. Assim, trabalhouse na calça para que ela não interferisse nessa possível dificuldade, ou para que interferisse o mínimo. O tecido também permitiu que a peça desenhasse melhor o corpo da modelo, trazendo assim um aumento na autoestima da mesma, pois as calças que são adaptadas não tem o mesmo caimento que a calça produzida. A calça foi confeccionada com fechamento em zíper e botão, e a entrevistada não relatou problemas com o manuseio.

Imagem 15 - Calça pronta.

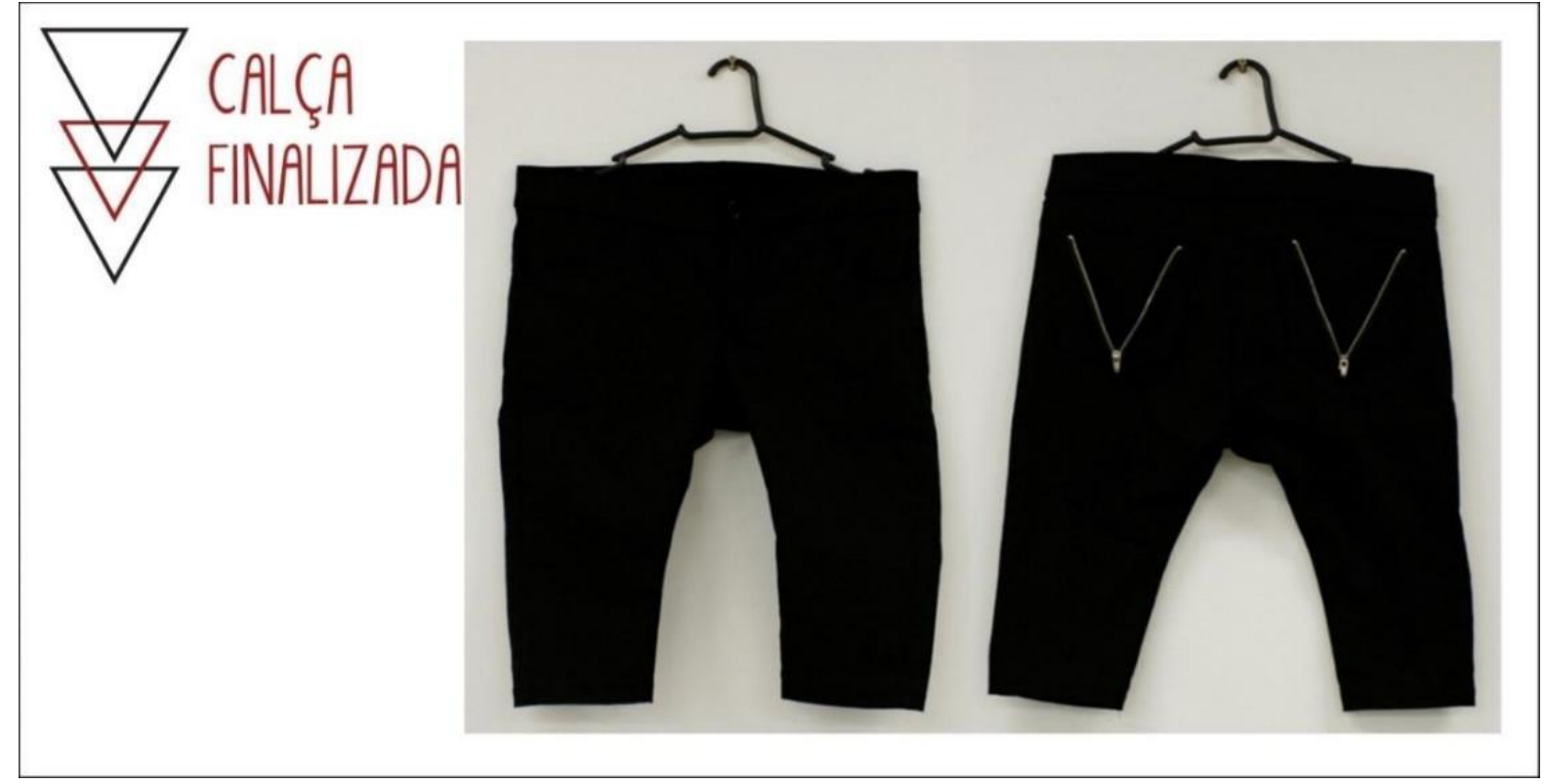

Fonte: autoras (2017).

A entrevistada provou a calça e aprovou o caimento, relatando seu desejo por peças semelhantes em seu guarda-roupa. Além de mencionar, posteriormente, que a usa com frequência, que o tecido não sofreu modificações e que a calça se mantém confortável durante o tempo de uso.

$\mathrm{Na}$ construção do look (imagem 16), produziu-se, simultaneamente, uma blusa para complementar o visual. Gerada a partir da tendência de blocos de cores, em que a cor central da blusa foi mantida na cor preta, a fim de que se criasse um alongamento vertical e um encolhimento horizontal, de modo a valorizar ainda mais o corpo da modelo. A blusa foi confeccionada em viscolycra, que é um tecido designado como malha fria (permite maior transpiração). A entrevistada informou que a blusa, assim como a calça, além de também ser confortável, é utilizada frequentemente. 
Imagem 16 - Modelo usando a calça.

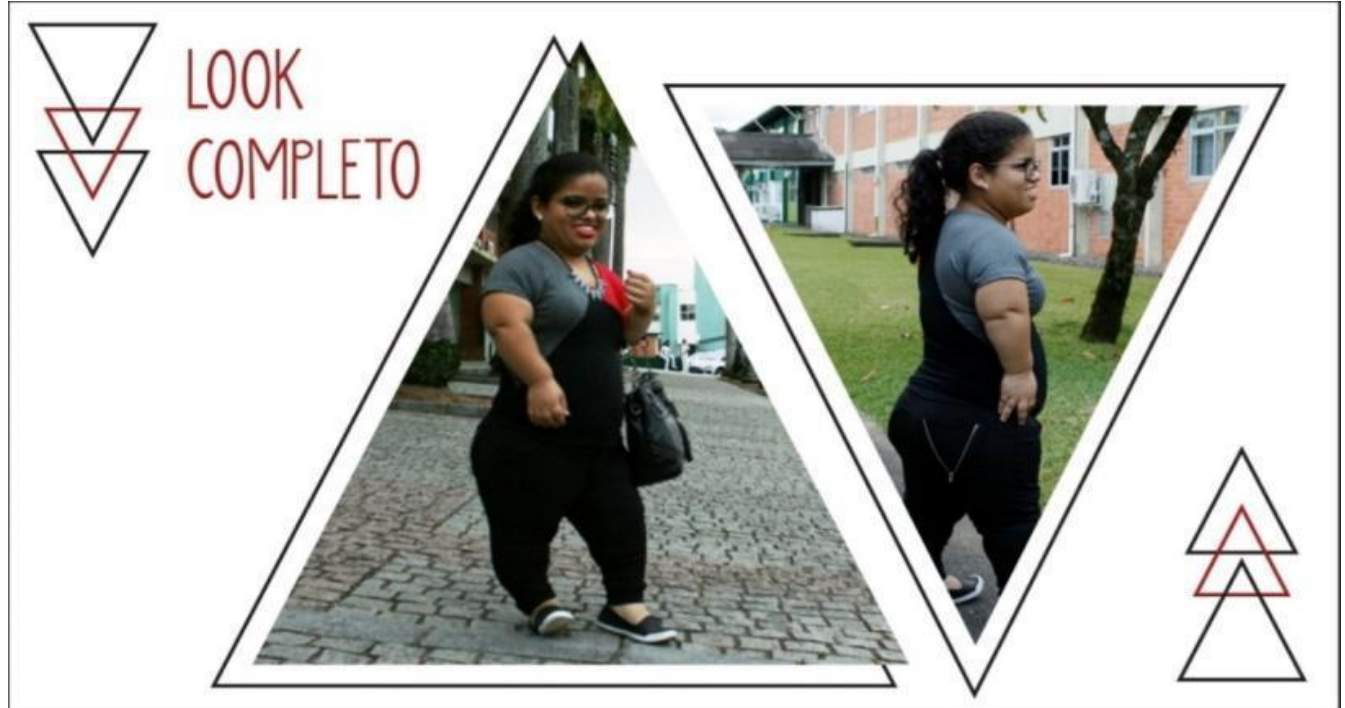

Fonte: autoras (2017).

\section{Considerações finais}

O presente trabalho teve como objetivo o desenvolvimento de uma peça para pessoas com nanismo, e para isso fez-se necessário pesquisar sobre a deficiência, problemas emocionais que ela causa, pesquisas já feitas sobre o assunto e tabelas de medidas já destinadas para o público, além de pesquisas de tendências para o verão 2018/19. Depois da coleta dos dados, confeccionouse uma peça de acordo com a pesquisa feita e que levou em conta a ergonomia como um fator diferencial. Produziu-se, então, uma calça pensada exclusivamente para mulheres com nanismo.

O trabalho exigiu pesquisas na área de moda inclusiva, e sobre como a moda pode contribuir para as mulheres disporem de uma maior autoaceitação, sentindo-se melhores consigo mesmas. Bem como foi interessante observar a falta de lojas que vendam artigos de moda destinados a este público em específico, mesmo com tantas pesquisas sobre moda inclusiva. Infelizmente este público depende, ainda, das suas costureiras de confiança. Mas espera-se que uma maior quantidade de estudos seja realizada, para conscientizar o mercado, e assim, incluir cada vez mais pessoas com nanismo na esfera da moda.

\section{Referências}

ADELSON, Betty M.. Medical and Psychosocial Aspects of Profound Short Stature. Baltimore: The Johns Hopkings University Press, 2005.

BÜLL, Patrícia. Estilista que faz roupa para anão quer ampliar com lingerie e loja virtual. In: Uol Economia, 2018. (https://economia.uol.com.br/empreendedorismo/noticias/redacao/2018/02/14/vestuarioconfeccao-roupas-pessoas-com-nanismo.htm)

CAMARGO, Priscila Aparecida K. Pinto; VALENTE, Eunice Lopez. A moda como fator de inclusão social de mulheres portadoras de Acondroplasia. In: Colóquio de moda, 2011. 
(http://www.coloquiomoda.com.br/anais/anais/7-Coloquio-de-Moda_2011/GT03/ComunicacaoOral/CO_89471A_Moda_como_Fator_de_Inclusao_Social_das_Mulheres_Portadoras_de_Acondr oplasia_.pdf).

El País. Aqui ninguém quer ser grande. In: El País, 2016. (https://brasil.elpais.com/brasil/2016/05/25/politica/1464189654_366336.html)

GASPARIN, Gabriela. Estilista busca espaço no mercado com grife destinada a pessoas com nanismo. In: Portal G1, 2011. (http://g1.globo.com/economia/pme/noticia/2011/04/estilistabusca-espaco-no-mercado-com-grife-para-pessoas-com-nanismo.html)

HELENA, Maria. Nanismo. In: Drauzio Varella, 2017. (https://drauziovarella.com.br/doencas-esintomas/nanismo/)

KÖRBES, Rafael; Laschuk, Tatiana, Neves, Thays C. Estudo de modelagem plana para pessoas com nanismo. In: Revista Icônica, 2015. (http://revistas.utfpr.edu.br/ap/index.php/iconica/article/view/20)

LAGÔA, Tatiana. Desfile de moda inclusiva movimenta universidade. In: O tempo, 2010. (http://www.otempo.com.br/cidades/desfile-de-moda-inclusiva-movimenta-universidade-

1.236284)

Portal G1. Desfile com modelos anãs em Paris combate 'padrões de beleza'. In: Portal G1, 2015. (http://g1.globo.com/mundo/noticia/2015/10/desfile-com-modelos-anas-em-paris-combatepadroes-de-beleza.html)

Portal Use Fashion. Elegância em movimento, peças-chave e pontos fortes. In: Portal Use Fashion, 2017. (http://www.usefashion.com/Categorias/ListaConteudos.aspx?IDCategoria=87\&IDTemporada=11 9

Revista Brasileira de Ergonomia. Definição Internacional de Ergonomia. In: ABERGO, 2008. (http://www.abergo.org.br/revista/index.php/ae/article/view/61/58)

SABRÁ, Flávio. Modelagem: tecnologia em produção do vestuário. São Paulo: Estação das Letras e Cores, 2009. 